\title{
Gnotobiotic Rodents: An In Vivo Model for the Study of Microbe-Microbe Interactions
}

\author{
Rebeca Martín*, Luis G. Bermúdez-Humarán and Philippe Langella \\ Micalis Institute, INRA, AgroParisTech, Université Paris-Saclay, Jouy-en-Josas, France
}

Germ-free rodents have no microorganisms living in or on them, allowing researchers to specifically control an animal's microbiota through the direct inoculation of bacteria of interest. This strategy has been widely used to decipher host-microbe interactions as well as the role of microorganisms in both (i) the development and function of the gut barrier (mainly the intestinal epithelium) and (ii) homeostasis and its effects on human health and disease. However, this in vivo model also offers a more realistic environment than an assay tube in which to study microbe-microbe interactions, without most of

Edited by:

Nuria Salazar,

Instituto de Productos Lácteos de Asturias - Centro de Investigación del Consejo Superior de Investigaciones Científicas, Spain

Reviewed by: Valentina Tremaroli, University of Gothenburg, Sweden Lihui Feng, Washington University in St. Louis,

Amanda Ellen Ramer-Tait, University of Nebraska-Lincoln, USA

*Correspondence: Rebeca Martín

rebeca.martinrosique@jouy.inra.fr

Specialty section:

This article was submitted to Microbial Physiology and Metabolism, a section of the journal

Frontiers in Microbiology

Received: 06 November 2015 Accepted: 14 March 2016 Published: 31 March 2016

Citation: Martín R, Bermúdez-Humarán LG and Langella P (2016) Gnotobiotic Rodents: An In Vivo Model for the Study of Microbe-Microbe Interactions. Front. Microbiol. 7:409. doi: 10.3389/fmicb.2016.00409 the confounding interactions present in the intestinal microbiota of conventionally raised mice. This review highlights the usefulness of controlled-microbiota mice in studying microbe-microbe interactions. To this end, we summarize current knowledge on germfree animals as an experimental model for the study of the ecology and metabolism of intestinal bacteria as well as of microbe-microbe interactions.

Keywords: germ-free, gnotobiology, bacterial interactions, intestinal bacteria, microbiota

\section{INTRODUCTION}

Like human beings, conventional rodents harbor trillions of bacteria and viruses (Williams, 2014). Germ-free (GF) animals, instead, are completely free of these microbes. In the field of gnotobiology [from the Greek "gnōtos" (known) and "biotic" (life)] (Gustafsson, 1959), such animals are used to study the effects of inoculation with specific, known microbes. To raise GF mice, researchers must separate pups from their mother's wombs surgically, by aseptic cesarean or hysterectomy, thus avoiding contact with microorganisms present in the mother's vagina and skin. Alternatively, GF pups can also be generated via the process of embryo transfer, which occurs in an isolator environment and thus enables the implantation of cleansed embryos into GF recipients under well-controlled conditions. A recipient female gives birth normally and cares for the offspring as if they were her own pups, thus enhancing the pups' survival rate. GF pups are kept in a sterile environment their whole lives. In order to guarantee GF status, recurrent contamination tests are performed on their feces. Once GF animals have been produced, it is possible to expand the colony by crossing GF individuals. The new members of the colony have a natural birth and continue their life under the same sterile conditions as their progenitors.

The accuracy of GF technology lies in the ability to control the composition of the environment in which an organism develops and functions (Falk et al., 1998). To this end, gnotobiotic facilities eliminate microbes present in food, water, and bedding through specific sterilization protocols. Typically, these materials are heated to temperatures above $100^{\circ} \mathrm{C}$ in order to kill 
bacteria and viruses. Possible contamination is prevented through a fail-safe double-door system, in which autoclaved supply cylinders are docked to a double-door port built into the isolator wall. These security measures enable inoculation by a single microorganism of interest, as well as the consequent reproduction of mono-associated animals, known as monoxenics. Animals inoculated with two microorganisms are known as dixenics, those with three are trixenics, and so on (Figure 1A) In the 1960s, Schaedler (Rockefeller University) investigated the effects of different mixtures of bacteria in GF mice. He was the first to study how a specific bacterium colonizes the gut of initially GF mice (Schaedler et al., 1965a,b), and his descriptions of what subsequently became known as the "Schaedler flora" have served as important tools in standardizing the microbiota of laboratory populations of rodents around the world (Schaedler et al., 1965a,b). This microbiota has recently been updated to include extremely oxygen-sensitive (EOS) bacteria, which were not included in the first survey due to the technical difficulties inherent in their isolation (Wymore Brand et al., 2015). Nowadays, this altered Schaedler microbiota (ASF) is used in several laboratories around the world for the study of bacteria-host dynamics (Wymore Brand et al., 2015). In addition, the ability to control the microbiota also enables the transfer of a simplified or complete human microbiota to the GF animals in order to create human-like conditions (Goodman et al., 2011) (Figure 1B). However, if the transferred microbiota is not completely defined, the resulting animals are not considered gnotobiotic animals.

Typically, gnotobiotic animals are used to study the effects of different members of the microbiota on the host. As is the case with most biological research (Williams, 2014), the field of gnotobiotics began with studies in which the system of interestin this case, the microbiota of various animals such as mice, rats, guinea pigs, and chicks-was removed in order to examine its role in different processes (Reyniers, 1959).

Studies with these animals have demonstrated that the crosstalk between microbes and their host is essential for the well-being of the host, and have indicated that the physiology of healthy host individuals is dependent on the composition of the gut microbiota. Indeed, changes in the gut microbiota affect processes as varied as epithelial cell renewal, differentiation, and architecture (Cherbuy et al., 2010); intestinal motility (Falk et al., 1998); and host glycosylation patterns and gene expression (Hooper et al., 2001). The study of gnotobiotic rodents has also allowed researchers to identify and characterize key microbes responsible for the development of the intestinal immune system (Umesaki and Setoyama, 2000; Umesaki, 2014). Thanks to gnotobiology, it is now widely recognized that the microbiome serves its hosts in capacities that go far beyond its role in food digestion. GF animals have dramatic alterations in practically every phenotype that has been studied, including the immune system, brain development, metabolism, behavior, and the function of the heart, lungs, and lymph nodes (Williams, 2014). In addition, the combination of gnotobiotic techniques with other new approaches has revealed causative associations between alterations in the commensal microbiota and diseases such as inflammatory bowel disease (IBD), obesity, and multiple sclerosis, among others (Balish and Warner, 2002; Ley et al., 2006; Turnbaugh et al., 2006; Berer et al., 2011).

\section{WHY USE GNOTOBIOTIC RODENTS IN STUDIES OF MICROBE-MICROBE INTERACTIONS?}

In the mammalian gut, microbes exist in a complex network of cooperation and competition. Simplified experimental culture conditions, in many cases, do not adequately represent the in vivo activities and connections among different members of the network, which prevents accurate evaluations of their individual contributions to overall microbiota functionality (Stecher et al., 2013a). Instead, gnotobiology offers a model in which microbemicrobe interactions can be assessed directly in a more complex environment. Furthermore, the use of initially GF animals enables complete knowledge of the microbial composition of a host, with consequent advantages for the interpretation of results compared to studies of conventional mice. For all these reasons, gnotobiotic studies offer a wide range of advantages compared to both other animal models and in vitro conditions. Gnotobiotics represents the optimal compromise between the realistic complexity of conventional rodents and the controlled nature of in vitro tests, without the incomplete knowledge and control of the environment inherent in the former and the oversimplifications of the latter.

\section{Gnotobiotics as a Model of Synergistic Microbial Interactions (Cooperative Network Analysis)}

The diverse intestinal microbiota is characterized by extensive synergistic ecological interactions (Stecher et al., 2013a). Gnotobiotic animals have been employed for deeper analyses of these important microbial interactions, in particular (i) bacterial succession, (ii) cross-feeding, and (iii) phage regulation of bacterial populations.

Most studies of bacterial succession have focused on the initial gut colonization process (primo-colonization; Fanaro et al., 2003). In these studies, different bacteria are introduced (sequentially or not) into GF animals in order to mimic the progressive colonization of the sterile intestine that begins immediately after birth. For instance, Tomas et al. (2013) compared the transfer of two different microbiota to GF rats: one from suckling rats, rich in early colonizing bacteria, and the other obtained from adult rats, representative of a mature microbiota. In rats with the early colonizing microbiota, strictly anaerobic bacteria succeeded aero-tolerant bacteria. Because of this coordinated process of bacterial succession, at the end of the experiment the microbiotas of both groups had converged on the same species profile, that of the mature inoculum. Similar results have been described for the process of microbiota acquisition in conventional mice (Gillilland et al., 2012). However, the mechanisms behind this succession remain poorly described, as this study focused only on host responses and not the evolution in microbe-microbe interactions (Tomas et al., 2013). 


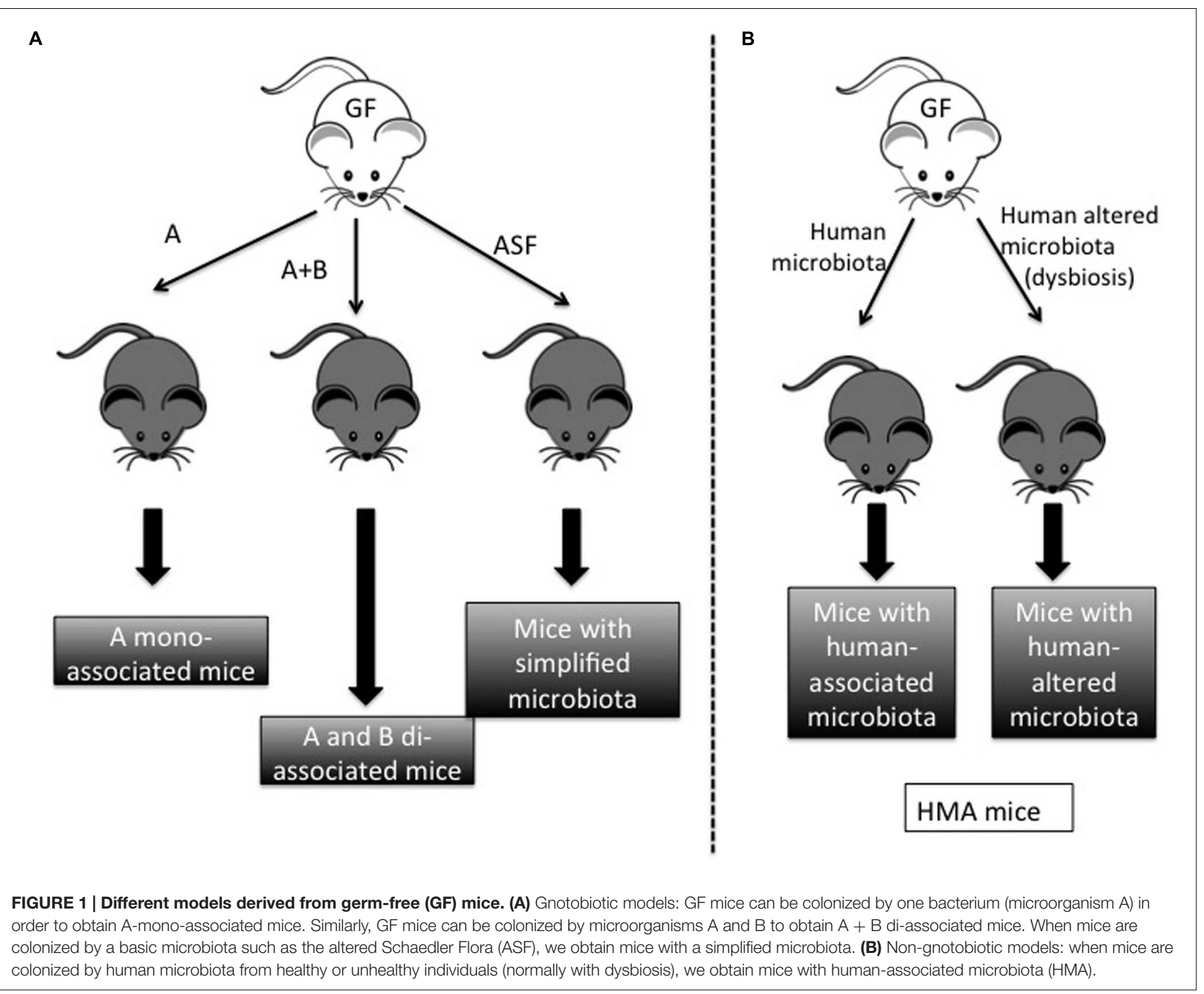

Aero-tolerant bacteria are thought to "prepare" the colonic environment for the growth of the strictly anaerobic bacteria that will later predominate. Researchers have taken advantage of this phenomenon to introduce certain strictly anaerobic bacteria into mice with a controlled microbiota. For example, the bacterium Faecalibacterium prausnitzii has well-known antiinflammatory properties that contribute to its role as a sensor and promoter of intestinal health (Miquel et al., 2013, 2014). However, because it is EOS, it is quite difficult to obtain monoxenic $F$. prausnitzii-associated rodents. By preparing the environment with Escherichia coli, though, Miquel et al. (2015) were able to generate gnotobiotic mice that harbored both F. prausnitzii and E. coli. Similarly, dixenic F. prausnitziiassociated rats were also obtained by first inoculating the rats with Bacteroides thetaiotaomicron (Wrzosek et al., 2013) (Figure 2). B. thetaiotaomicron is an anaerobic bacterium; rather, it decreases the oxido-reductive potential of the gastrointestinal tract (GIT), thus enabling colonization by F. prausnitzii. In addition, B. thetaiotaomicron and F. prausnitzii complement each other metabolically: the former is acetate-producing whereas the latter is acetate-consuming and butyrate-producing (Duncan et al., 2002; Mahowald et al., 2009). In di-associated rats, $B$. thetaiotaomicron produces acetate and $F$. prausnitzii transforms this into butyrate (Wrzosek et al., 2013). These short-chain fatty acids (SCFAs) are also able to stimulate the host response. For instance, SCFA trigger pleiotropic signals in the host, including signals regulating mucin synthesis and secretion (Gaudier et al., 2004; Burger-van Paassen et al., 2009). Both of these dixenic models illustrate the importance of bacterial interactions during the colonization of GF rodents by microorganisms. Since strictly anaerobic bacteria are major components of the intestinal microbiota, these mutualistic relationships are likely of vital importance in microbiota acquisition and maintenance.

As mentioned above, the study of bacterial cross-feeding phenomena is one area in which the tools of gnotobiology will continue to be indispensable. Special models of human microbiota have been developed for this purpose, as only $15 \%$ of 


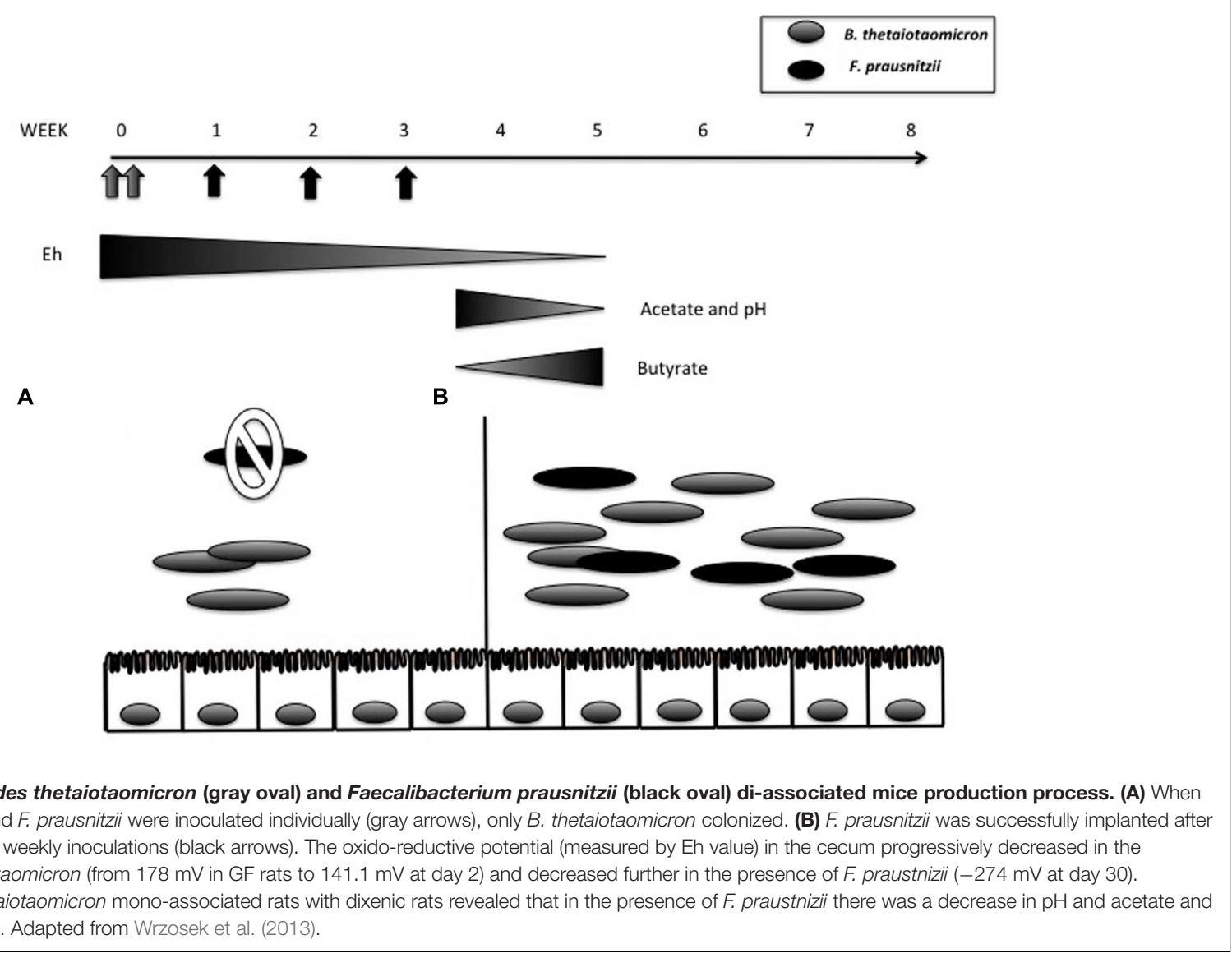

the bacterial species found in mice are also present in humans (Tomas et al., 2012). Human microbiota-associated (HMA) mice have also been employed as models in the study of the ecology and metabolism of the human intestinal microbiota (Hirayama and Itoh, 2005). For instance, studies of GF mice colonized by human microbiota have clarified the cross-feeding activities of Akkermansia muciniphila (Van den Abbeele et al., 2011), a highly specialized bacterium capable of utilizing mucus as a sole carbon and nitrogen source (Derrien et al., 2004; Everard et al., 2013). The mucus-degrading ability of A. muciniphila and its localization within the mucus layer have revealed its specific niche and function within the gut (Swidsinski et al., 2009; Png et al., 2010). By degrading mucus, A. muciniphila has the ability to produce SCFAs (acetate and propionate) (Derrien et al., 2004), which can stimulate microbiota interactions and a host response. Specifically, oligosaccharides and acetate stimulate growth and metabolic activity in commensal bacteria growing close to the mucus layer, which may in turn discourage pathogenic bacteria from crossing the mucus layer to reach the intestinal cells (Derrien et al., 2004, 2010, 2011). Furthermore, an increase in acetate and propionate due to the degradation of mucus by A. muciniphila could stimulate other bacterial groups with well-known butyrate-producing capacities as it has been proved in vitro with other acetate producers (Rios-Covian et al., 2015).

Other scientific research on the human microbiome has stimulated interest in probiotics, health-promoting agents that are able to modulate the intestinal microbiota. In a recent experiment, HFA mice were used to study the ability of Bifidobacterium longum strain BB536 to modulate the gut environment (Sugahara et al., 2015). HFA mice that were supplemented with strain BB536 showed increased fecal levels of butyrate and pimelate, a precursor of biotin. In addition, the BB536-supplemented mice also had metabolic alterations related to biotin synthesis, specifically involving Bacteroides caccae and the increased prevalence of Eubacterium rectale, a butyrate producer (Sugahara et al., 2015). All these possible interactions of B. longum BB536 with the microbial community might explain, at least in part, various reports of its beneficial physiological effects on the host, including anti-allergy effects, competition against harmful bacteria, and improvement in defecation frequency and stool characteristics (Odamaki et al., 2007, 2012; Xiao et al., 2007; Namba et al., 2010).

Gnotobiotics also offers clear advantages for the study of phage-bacteria dynamics in the human gut. Bacterial viruses (phages) are the most abundant biological group on earth (Rodriguez-Valera et al., 2009). In some ecosystems, they are capable of maintaining high levels of diversity of bacterial strains through lysis of their hosts, in a process described by the constant-diversity dynamics model of bacterial diversity; this model is based on the fact that many of the genes that differ between strains affect regions that are potential phage recognition targets (Rodriguez-Valera et al., 2009). Recently, 
Reyes and coworkers introduced sequenced human gut bacteria into GF mice and followed this with a controlled phage attack using virus-like particles (VLPs) purified from the fecal microbiota (Rodriguez-Valera et al., 2009).The authors observed transient changes in bacterial community structure and bacterial acquisition of resistance to phage attack through both ecological and epigenetic mechanisms. These results illustrate the utility of gnotobiotic mice in characterizing ecological relationships among all components in the gut, viruses as well as bacteria.

\section{Gnotobiotic Animals as Models of Antagonistic Microbial Interactions (Competitive Network Analysis)}

Microbe-microbe interactions are not always cooperative. Antagonistic cross-talk is a fundamental link in microbial ecology and vital for the maintenance of host health. Gnotobiotic animals have been employed to obtain deeper insight into the ability of the microbiota to protect against infections, a process termed colonization resistance (Stecher et al., 2013b).

Alterations in microbiota homeostasis generally result in dysbiosis, an imbalance among bacterial species that often occurs in the digestive tract. This condition, also known as dysbacteriosis, is associated with illnesses such as IBD, chronic obesity, cancer, and bacterial vaginosis (Martin et al., 2013, 2014a,b). Efforts to link these diseases to specific changes in the microbiota have been hindered, though, by a lack of knowledge of healthy bacterial communities. Indeed, it is not well understood if dysbiosis itself is a consequence or a cause of an imbalance in bacteria-bacteria relationships in the gastrointestinal tract.

When colonization resistance is disrupted through antibioticmediated perturbations in the microbiota or other similar phenomena, infections by nosocomial pathogens tend to increase (Ubeda and Pamer, 2012; Stecher et al., 2013b). This observation could be explained by the 1983 proposal of Freter et al. (1983a,b) that populations of most intestinal bacteria are held in check by competition for limited substrates. GF animals provide an ideal testing ground in which to explore this hypothesis, as the level of competition within a particular host can be manipulated through the introduction of varying numbers of bacterial strains. Studies using this approach have found that, because they lack competing bacterial species, GF animals are more susceptible than conventional ones to infections by E. coli, Clostridium difficile, Vibrio cholerae, or Citrobacter rodentium (Collins and Carter, 1978; Butterton et al., 1996; Stecher et al., 2005; Kamada et al., 2012; Reeves et al., 2012). This hypothesis was further supported by experiments in which the transplantation of healthy fecal microbiota increased host resistance (Barman et al., 2008; Endt et al., 2010; Lawley et al., 2012). Thus, Freter's theory provides a straightforward explanation of why gnotobiotic mice are more sensitive to nosocomial infections: the lack of substrate competition reduces barriers to colonization. However, this conclusion is probably over-simplistic. Nowadays, studies from various fields, including gnotobiology, have concluded that colonization resistance is the result of not only a highly complex interplay among members of the commensal microbiota, but also of interactions among the microbiome [the entire community of microbes and their genetic material; (Martin et al., 2014a), the intestinal mucosa, and the immune system (Stecher et al., 2013b)]. For example, GF mice have been used to examine how individual bacteria species or bacterial communities influence colonization resistance to $C$. difficile. In particular, GF mice that had been inoculated only with a murine isolate from the family Lachnospiraceae demonstrated partially restored colonization resistance to $C$. difficile (Reeves et al., 2012), confirming that the indigenous microbial community of the GIT and the interrelationships among its members determine susceptibility to colonization and growth of C. difficile (Reeves et al., 2011, 2012). These results highlight the potential of gnotobiotic mice as a controlled environment in which to study antagonist microbial interactions.

Colonization resistance is not the only example of antagonistic interactions in the microbiota. For example, gnotobiotic models have also been used to analyze growth competition between the well-known yoghurt bacteria Streptococcus thermophilus and Lactobacillus delbrueckii ssp. bulgaricus. The growth and lactate production of these two bacteria were monitored in different media and in the GIT of GF rats. When GF rats were not supplemented with lactose, they were colonized only by S. thermophilus, not by L. bulgaricus. However, when the rats' drinking water was supplemented with lactose, both bacteria were able to colonize. Interestingly, when lactose-supplemented GF rats were inoculated with a mix of both bacteria, S. thermophilus colonized the GIT faster and more extensively than L. bulgaricus did. This work showed that $S$. thermophilus has a competitive and growth advantage over L. bulgaricus in vitro as well as in vivo in the GIT of GF rats (Ben-Yahia et al., 2012).

\section{FUTURE TRENDS IN GNOTOBIOLOGY}

At this point, gnotobiology is a mature science with applications that go far beyond conventional ones. The classical experiments and protocols used routinely in the study of microbes' interactions with their hosts can easily be modified in order to investigate interactions between and among multiple members of the microbiota. As an example, a study aiming to understand the effect of a microbe of interest on a particular disease would benefit greatly from the use of mice with a controlled, described microbiota. Such mice would then also be the perfect experimental system in which to analyze the relationship of the same microbe with the rest of the microbiota. Furthermore, this analysis could be performed in both healthy and diseased hosts. Similarly, our understanding of a pathogen's activity in a host could be enhanced through the use of various monoxenic mice: such mice could be infected with a pathogen and monitored in order to directly assess the effect of individual resident microorganisms on the disease caused by the pathogen. This model presents unique opportunities to analyze the possible antagonistic interactions between resident and invading microorganisms.

In brief, the options with gnotobiology are almost unlimited. Furthermore, the combination of gnotobiotics with newomics approaches (e.g., transcriptomics, metabolomics, and 
genomics) and molecular genetics (genetically modified mice and bacteria) could provide important insights into the roles of microbe-microbe interactions. This knowledge could improve our understanding of how commensal bacteria change into opportunistic pathogens, how pathogens are able to proliferate, and how probiotic bacteria could help to resolve dysbiosis.

\section{CONCLUDING REMARKS}

Here, we have summarized the most important outcomes of gnotobiological research in the field of microbe-microbe interactions as well as other concerns with relevance to the field. The most significant questions in microbiota analysis, including microbial interaction, rely on gnotobiotic animals for further advancements in the field. GF animals will be indispensable in future investigations of how certain microorganisms are able to

\section{REFERENCES}

Balish, E., and Warner, T. (2002). Enterococcus faecalis induces inflammatory bowel disease in interleukin-10 knockout mice. Am. J. Pathol. 160, 2253-2257. doi: 10.1016/S0002-9440(10)61172-8

Barman, M., Unold, D., Shifley, K., Amir, E., Hung, K., Bos, N., et al. (2008). Enteric salmonellosis disrupts the microbial ecology of the murine gastrointestinal tract. Infect. Immun. 76, 907-915. doi: 10.1128/IAI.01432-07

Ben-Yahia, L., Mayeur, C., Rul, F., and Thomas, M. (2012). Growth advantage of Streptococcus thermophilus over Lactobacillus bulgaricus in vitro and in the gastrointestinal tract of gnotobiotic rats. Benef. Microbes 3, 211-219. doi: 10.3920/BM2012.0012

Berer, K., Mues, M., Koutrolos, M., Rasbi, Z. A., Boziki, M., Johner, C., et al. (2011). Commensal microbiota and myelin autoantigen cooperate to trigger autoimmune demyelination. Nature 479, 538-541. doi: 10.1038/nature10554

Burger-van Paassen, N., Vincent, A., Puiman, P. J., van der Sluis, M., Bouma, J., Boehm, G., et al. (2009). The regulation of intestinal mucin MUC2 expression by short-chain fatty acids: implications for epithelial protection. Biochem. J. 420, 211-219. doi: 10.1042/BJ20082222

Butterton, J. R., Ryan, E. T., Shahin, R. A., and Calderwood, S. B. (1996). Development of a germfree mouse model of Vibrio cholerae infection. Infect. Immun. 64, 4373-4377.

Cherbuy, C., Honvo-Houeto, E., Bruneau, A., Bridonneau, C., Mayeur, C., Duee, P. H., et al. (2010). Microbiota matures colonic epithelium through a coordinated induction of cell cycle-related proteins in gnotobiotic rat. Am. J. Physiol. Gastrointest. Liver Physiol. 299, G348-G357. doi: 10.1152/ajpgi.00384.2009

Collins, F. M., and Carter, P. B. (1978). Growth of Salmonellae in orally infected germfree mice. Infect. Immun. 21, 41-47.

Derrien, M., Van Baarlen, P., Hooiveld, G., Norin, E., Muller, M., and de Vos, W. M. (2011). Modulation of mucosal immune response, tolerance, and proliferation in mice colonized by the mucin-degrader Akkermansia muciniphila. Front. Microbiol. 2:166. doi: 10.3389/fmicb.2011.00166

Derrien, M., van Passel, M. W., van de Bovenkamp, J. H., Schipper, R. G., de Vos, W. M., and Dekker, J. (2010). Mucin-bacterial interactions in the human oral cavity and digestive tract. Gut Microbes 1, 254-268. doi: 10.4161/gmic.1.4.12778

Derrien, M., Vaughan, E. E., Plugge, C. M., and de Vos, W. M. (2004). Akkermansia muciniphila gen. nov., sp. nov., a human intestinal mucin-degrading bacterium. Int. J. Syst. Evol. Microbiol. 54, 1469-1476. doi: 10.1099/ijs.0.02873-054/5/1469

Duncan, S. H., Hold, G. L., Harmsen, H. J., Stewart, C. S., and Flint, H. J. (2002). Growth requirements and fermentation products of Fusobacterium prausnitzii, and a proposal to reclassify it as Faecalibacterium prausnitzii gen. nov., comb. nov. Int. J. Syst. Evol. Microbiol. 52, 2141-2146. doi: 10.1099/00207713-52-62141

Endt, K., Stecher, B., Chaffron, S., Slack, E., Tchitchek, N., Benecke, A., et al. (2010). The microbiota mediates pathogen clearance from the gut colonize and survive in the host, while others, e.g., pathogens, are not. Studies of interaction and communication within the microbiota will also depend heavily on gnotobiotic approaches.

\section{AUTHOR CONTRIBUTIONS}

$\mathrm{RM}, \mathrm{LB}-\mathrm{H}$, and PL designed the mini-review. RM wrote the manuscript. LB-H and PL corrected the manuscript. All the authors approved the final version of the manuscript.

\section{ACKNOWLEDGMENT}

RM receives a salary from Danone Nutricia Research in the framework of a postdoc contract.

lumen after non-typhoidal Salmonella diarrhea. PLoS Pathog. 6:e1001097. doi: 10.1371/journal.ppat.1001097

Everard, A., Belzer, C., Geurts, L., Ouwerkerk, J. P., Druart, C., Bindels, L. B., et al. (2013). Cross-talk between Akkermansia muciniphila and intestinal epithelium controls diet-induced obesity. Proc. Natl. Acad. Sci. U.S.A. 110, 9066-9071. doi: $10.1073 /$ pnas. 1219451110

Falk, P. G., Hooper, L. V., Midtvedt, T., and Gordon, J. I. (1998). Creating and maintaining the gastrointestinal ecosystem: what we know and need to know from gnotobiology. Microbiol. Mol. Biol. Rev. 62, 1157-1170.

Fanaro, S., Chierici, R., Guerrini, P., and Vigi, V. (2003). Intestinal microflora in early infancy: composition and development. Acta Paediatr. Suppl. 91, 48-55.

Freter, R., Brickner, H., Botney, M., Cleven, D., and Aranki, A. (1983a). Mechanisms that control bacterial populations in continuous-flow culture models of mouse large intestinal flora. Infect. Immun. 39, 676-685.

Freter, R., Brickner, H., Fekete, J., Vickerman, M. M., and Carey, K. E. (1983b). Survival and implantation of Escherichia coli in the intestinal tract. Infect. Immun. 39, 686-703.

Gaudier, E., Jarry, A., Blottiere, H. M., de Coppet, P., Buisine, M. P., Aubert, J. P., et al. (2004). Butyrate specifically modulates MUC gene expression in intestinal epithelial goblet cells deprived of glucose. Am. J. Physiol. Gastrointest. Liver Physiol. 287, G1168-G1174. doi: 10.1152/ajpgi. 00219.2004

Gillilland, M. G. I. I. I., Erb-Downward, J. R., Bassis, C. M., Shen, M. C., Toews, G. B., Young, V. B., et al. (2012). Ecological succession of bacterial communities during conventionalization of germ-free mice. Appl. Environ. Microbiol. 78, 2359-2366. doi: 10.1128/AEM.05239-11

Goodman, A. L., Kallstrom, G., Faith, J. J., Reyes, A., Moore, A., Dantas, G., et al. (2011). Extensive personal human gut microbiota culture collections characterized and manipulated in gnotobiotic mice. Proc. Natl. Acad. Sci. U.S.A. 108, 6252-6257. doi: 10.1073/pnas.1102938108

Gustafsson, B. E. (1959). Lightweight stainless steel systems for rearing germfree animals. Ann. N. Y. Acad. Sci. 78, 17-28. doi: 10.1111/j.17496632.1959.tb53092.x

Hirayama, K., and Itoh, K. (2005). Human flora-associated (HFA) animals as a model for studying the role of intestinal flora in human health and disease. Curr. Issues Intest. Microbiol. 6, 69-75.

Hooper, L. V., Wong, M. H., Thelin, A., Hansson, L., Falk, P. G., and Gordon, J. I. (2001). Molecular analysis of commensal host-microbial relationships in the intestine. Science 291, 881-884. doi: 10.1126/science.291.5505.881

Kamada, N., Kim, Y. G., Sham, H. P., Vallance, B. A., Puente, J. L., Martens, E. C., et al. (2012). Regulated virulence controls the ability of a pathogen to compete with the gut microbiota. Science 336, 1325-1329. doi: 10.1126/science.1222195

Lawley, T. D., Clare, S., Walker, A. W., Stares, M. D., Connor, T. R., Raisen, C., et al. (2012). Targeted restoration of the intestinal microbiota with a simple, defined bacteriotherapy resolves relapsing Clostridium difficile disease in mice. PLoS Pathog. 8:e1002995. doi: 10.1371/journal.ppat.1002995 
Ley, R. E., Turnbaugh, P. J., Klein, S., and Gordon, J. I. (2006). Microbial ecology: human gut microbes associated with obesity. Nature 444, 1022-1023. doi: 10.1038/4441022a

Mahowald, M. A., Rey, F. E., Seedorf, H., Turnbaugh, P. J., Fulton, R. S., Wollam, A., et al. (2009). Characterizing a model human gut microbiota composed of members of its two dominant bacterial phyla. Proc. Natl. Acad. Sci. U.S.A. 106, 5859-5864. doi: 10.1073/pnas.0901529106

Martin, R., Miquel, S., Langella, P., and Bermudez-Humaran, L. G. (2014a). The role of metagenomics in understanding the human microbiome in health and disease. Virulence 5, 413-423. doi: 10.4161/viru.27864

Martin, R., Miquel, S., Ulmer, J., Kechaou, N., Langella, P., and BermudezHumaran, L. G. (2013). Role of commensal and probiotic bacteria in human health: a focus on inflammatory bowel disease. Microb. Cell Fact. 12, 71. doi: 10.1186/1475-2859-12-71

Martin, R., Miquel, S., Ulmer, J., Langella, P., and Bermudez-Humaran, L. G. (2014b). Gut ecosystem: how microbes help us. Benef. Microbes 5, 219-233. doi: 10.3920/BM2013.0057

Miquel, S., Leclerc, M., Martin, R., Chain, F., Lenoir, M., Raguideau, S., et al. (2015). Identification of metabolic signatures linked to anti-inflammatory effects of Faecalibacterium prausnitzii. Mbio 6, e00300-e00315. doi: 10.1128/mBio.00300-15

Miquel, S., Martin, R., Bridonneau, C., Robert, V., Sokol, H., Bermudez-Humaran, L. G., et al. (2014). Ecology and metabolism of the beneficial intestinal commensal bacterium Faecalibacterium prausnitzii. Gut Microbes 5, 146-151. doi: 10.4161 /gmic. 27651

Miquel, S., Martin, R., Rossi, O., Bermudez-Humaran, L. G., Chatel, J. M., Sokol, H., et al. (2013). Faecalibacterium prausnitzii and human intestinal health. Curr. Opin. Microbiol. 16, 255-261. doi: 10.1016/j.mib.2013.06.003

Namba, K., Hatano, M., Yaeshima, T., Takase, M., and Suzuki, K. (2010). Effects of Bifidobacterium longum BB536 administration on influenza infection, influenza vaccine antibody titer, and cell-mediated immunity in the elderly. Biosci. Biotechnol. Biochem. 74, 939-945. doi: 10.1271/bbb.90749

Odamaki, T., Sugahara, H., Yonezawa, S., Yaeshima, T., Iwatsuki, K., Tanabe, S., et al. (2012). Effect of the oral intake of yogurt containing Bifidobacterium longum BB536 on the cell numbers of enterotoxigenic Bacteroides fragilis in microbiota. Anaerobe 18, 14-18. doi: 10.1016/j.anaerobe.2011.11.004

Odamaki, T., Xiao, J. Z., Iwabuchi, N., Sakamoto, M., Takahashi, N., Kondo, S., et al. (2007). Influence of Bifidobacterium longum BB536 intake on faecal microbiota in individuals with Japanese cedar pollinosis during the pollen season. J. Med. Microbiol. 56, 1301-1308. doi: 10.1099/jmm.0.47306-0

Png, C. W., Linden, S. K., Gilshenan, K. S., Zoetendal, E. G., McSweeney, C. S., Sly, L. I., et al. (2010). Mucolytic bacteria with increased prevalence in IBD mucosa augment in vitro utilization of mucin by other bacteria. Am. J. Gastroenterol. 105, 2420-2428. doi: 10.1038/ajg.2010.281

Reeves, A. E., Koenigsknecht, M. J., Bergin, I. L., and Young, V. B. (2012). Suppression of Clostridium difficile in the gastrointestinal tracts of germfree mice inoculated with a murine isolate from the family Lachnospiraceae. Infect. Immun. 80, 3786-3794. doi: 10.1128/IAI.00647-12

Reeves, A. E., Theriot, C. M., Bergin, I. L., Huffnagle, G. B., Schloss, P. D., and Young, V. B. (2011). The interplay between microbiome dynamics and pathogen dynamics in a murine model of Clostridium difficile Infection. Gut Microbes 2, 145-158. doi: 10.4161/gmic.2.3.16333

Reyniers, J. A. (1959). The pure culture concept and gnotobiotics. Ann. N. Y. Acad. Sci. 78, 3-16.

Rios-Covian, D., Gueimonde, M., Duncan, S. H., Flint, H. J., and de Los ReyesGavilan, C. G. (2015). Enhanced butyrate formation by cross-feeding between Faecalibacterium prausnitzii and Bifidobacterium adolescentis. FEMS Microbiol. Lett. 362:fnv176. doi: 10.1093/femsle/fnv176

Rodriguez-Valera, F., Martin-Cuadrado, A. B., Rodriguez-Brito, B., Pasic, L., Thingstad, T. F., Rohwer, F., et al. (2009). Explaining microbial population genomics through phage predation. Nat. Rev. Microbiol. 7, 828-836. doi: $10.1038 /$ nrmicro2235

Schaedler, R. W., Dubos, R., and Costello, R. (1965a). Association of germfree mice with bacteria isolated from normal mice. J. Exp. Med. 122, 77-82. doi: 10.1084/jem.122.1.77

Schaedler, R. W., Dubos, R., and Costello, R. (1965b). The development of the bacterial flora in the gastrointestinal tract of mice. J. Exp. Med. 122, 59-66. doi: $10.1084 /$ jem.122.1.59
Stecher, B., Berry, D., and Loy, A. (2013a). Colonization resistance and microbial ecophysiology: using gnotobiotic mouse models and single-cell technology to explore the intestinal jungle. FEMS Microbiol. Rev. 37, 793-829. doi: 10.1111/1574-6976.12024

Stecher, B., Macpherson, A. J., Hapfelmeier, S., Kremer, M., Stallmach, T., and Hardt, W. D. (2005). Comparison of Salmonella enterica serovar Typhimurium colitis in germfree mice and mice pretreated with streptomycin. Infect. Immun. 73, 3228-3241. doi: 10.1128/IAI.73.6.3228-3241.2005

Stecher, B., Maier, L., and Hardt, W. D. (2013b). 'Blooming' in the gut: how dysbiosis might contribute to pathogen evolution. Nat. Rev. Microbiol. 11, 277-284. doi: 10.1038/nrmicro2989

Sugahara, H., Odamaki, T., Fukuda, S., Kato, T., Xiao, J. Z., Abe, F., et al. (2015). Bifidobacterium longum alters gut luminal metabolism through modification of the gut microbial community. Sci. Rep. 5:13548. doi: 10.1038/ srep 13548

Swidsinski, A., Ung, V., Sydora, B. C., Loening-Baucke, V., Doerffel, Y., Verstraelen, H., et al. (2009). Bacterial overgrowth and inflammation of small intestine after carboxymethylcellulose ingestion in genetically susceptible mice. Inflamm. Bowel Dis. 15, 359-364. doi: 10.1002/ibd.20763

Tomas, J., Langella, P., and Cherbuy, C. (2012). The intestinal microbiota in the rat model: major breakthroughs from new technologies. Anim. Health Res. Rev. 13, 54-63. doi: 10.1017/S1466252312000072

Tomas, J., Wrzosek, L., Bouznad, N., Bouet, S., Mayeur, C., Noordine, M. L., et al. (2013). Primocolonization is associated with colonic epithelial maturation during conventionalization. FASEB J. 27, 645-655. doi: 10.1096/fj.12216861

Turnbaugh, P. J., Ley, R. E., Mahowald, M. A., Magrini, V., Mardis, E. R., and Gordon, J. I. (2006). An obesity-associated gut microbiome with increased capacity for energy harvest. Nature 444, 1027-1031. doi: 10.1038/nature05414

Ubeda, C., and Pamer, E. G. (2012). Antibiotics, microbiota, and immune defense. Trends Immunol. 33, 459-466. doi: 10.1016/j.it.2012.05.003

Umesaki, Y. (2014). Use of gnotobiotic mice to identify, and characterize key microbes responsible for the development of the intestinal immune system. Proc. Jpn. Acad. Ser. B Phys. Biol. Sci. 90, 313-332. doi: 10.2183/pjab.90.313

Umesaki, Y., and Setoyama, H. (2000). Structure of the intestinal flora responsible for development of the gut immune system in a rodent model. Microbes Infect. 2, 1343-1351. doi: 10.1016/S1286-4579(00)01288-0

Van den Abbeele, P., Gerard, P., Rabot, S., Bruneau, A., El Aidy, S., Derrien, M., et al. (2011). Arabinoxylans and inulin differentially modulate the mucosal and luminal gut microbiota and mucin-degradation in humanized rats. Environ. Microbiol. 13, 2667-2680. doi: 10.1111/j.1462-2920.2011.02533.x

Williams, S. C. (2014). Gnotobiotics. Proc. Natl. Acad. Sci. U.S.A. 111, 1661. doi: $10.1073 /$ pnas.1324049111

Wrzosek, L., Miquel, S., Noordine, M. L., Bouet, S., Joncquel Chevalier-Curt, M., Robert, V., et al. (2013). Bacteroides thetaiotaomicron and Faecalibacterium prausnitzii influence the production of mucus glycans and the development of goblet cells in the colonic epithelium of a gnotobiotic model rodent. BMC Biol. 11:61. doi: 10.1186/1741-7007-11-61

Wymore Brand, M., Wannemuehler, M. J., Phillips, G. J., Proctor, A., Overstreet, A. M., Jergens, A. E., et al. (2015). The Altered Schaedler Flora: continued applications of a defined murine microbial community. ILAR J. 56, 169-178. doi: 10.1093/ilar/ilv012

Xiao, J. Z., Kondo, S., Yanagisawa, N., Miyaji, K., Enomoto, K., Sakoda, T., et al. (2007). Clinical efficacy of probiotic Bifidobacterium longum for the treatment of symptoms of Japanese cedar pollen allergy in subjects evaluated in an environmental exposure unit. Allergol. Int. 56, 67-75. doi: 10.2332/allergolint.O-06-455

Conflict of Interest Statement: The authors declare that the research was conducted in the absence of any commercial or financial relationships that could be construed as a potential conflict of interest.

Copyright (c) 2016 Martín, Bermúdez-Humarán and Langella. This is an open-access article distributed under the terms of the Creative Commons Attribution License (CC BY). The use, distribution or reproduction in other forums is permitted, provided the original author(s) or licensor are credited and that the original publication in this journal is cited, in accordance with accepted academic practice. No use, distribution or reproduction is permitted which does not comply with these terms. 